\title{
Re-examining Higher Education Internationalization in Taiwan: University Strategies for Implementing Overseas Programmes
}

\author{
Yuching Liao ${ }^{1}$ \\ ${ }^{1}$ Graduate School of Education, Kyoto Unviersity, Kyoto, Japan \\ Correspondence: Yuching Liao, Graduate School of Education, Kyoto University, Yoshida-Hommachi, \\ Sakyo-Ku, Kyoto, 606-8501, Japan. Tel: 81-80-4243-0168. E-mail: liao.yuching.64x @ st.kyoto-u.ac.jp
}

Received: August 1, 2018

Accepted: August 14, $2018 \quad$ Online Published: October 20, 2018

doi:10.5539/hes.v8n4p116

URL: https://doi.org/10.5539/hes.v8n4p116

\begin{abstract}
This study clarifies the rationale for offering overseas programmes as an internationalization strategy by Taiwanese higher education institutions through an analysis of related university documents and interview data. In doing so, this study highlights how institutional goals and characteristics, as well as social and cultural backgrounds, affect the internationalization of higher education based on the following two points. First, in addition to the pursuit of academic excellence and expanding student markets, university strategies are based on its particular history, resources, development goals, and orientation. Second, although different strategies were observed among the examined universities, the Chinese element and the pluralistic value of Taiwanese society have influenced the overseas programmes offered by Taiwanese universities. This paper argues that instead of merely adopting the international standard or pursuing academic excellence, it is essential for Taiwanese universities to implement internationalization strategies in order to determine their meaning and purpose in the context of Taiwanese higher education.
\end{abstract}

Keywords: cross-border education, higher education, internationalization, overseas programmes, Taiwan, universities' strategies

\section{Introduction}

As a result of the influence of globalization and the development of a neoliberal world economy and society, the internationalization of higher education has become a crucial global issue. The Taiwanese government has emphasized internationalization since the country joined the World Trade Organization in 2002, and the issues of expanding its higher education market and engaging in intense competition with overseas universities have since confronted Taiwanese society.

In 2003, the overseas programme was introduced to promote internationalization and raise awareness of the international student market. An overseas programme is a degree programme through which universities provide offshore education in cooperation with partner educational institutions. The programme constituted a new type of cross-border education, which the Taiwanese government viewed as a means of offering students flexibility and contributing to the internationalization of higher education. In 2016, the Taiwanese government established the 'New Southbound Policy', which expanded and deepened cooperation and exchange among Southeast Asian countries. Based on this policy, the Ministry of Education (MOE) advanced emphasized the need for an overseas programme as a platform to expand the recruitment of Southeast Asian students (MOE, 2016a).

However, these overseas programmes were not directly related to the general idea of internationalization in some respects, such as mainly targeting overseas students or offering courses in English. The overseas programmes also made Taiwanese overseas students their enrolment targets, while the majority were taught in Chinese. Previous research indicates that the Taiwanese government's policies of cross-border education were implemented not only in the interest of internationalization but also because of political and economic influences (Chan, 2011; Chen, 2013). Therefore, overseas programmes were initially implemented to help Taiwanese investors develop overseas industries and cultivate human resources (Chen, 2013). The findings of these studies have revealed the complicated nature of Taiwanese internationalization policies. However, few studies have examined the intentions of universities that have adopted overseas programmes, which served to meet the educational demands of overseas Taiwanese businesspeople and further internationalization. 
The response of universities to government policies is critical in determining the state of Taiwan's efforts towards the internationalization of higher education. Since the 1990s and the beginning of the era of democratization and liberalization in Taiwan, the authority of universities in Taiwan has expanded amid the trend of deregulation. Furthermore, because of amendments made to universities' guidelines for overseas programmes in 2010 and 2016, government restrictions on offering overseas programmes have been relaxed and universities have obtained more control over their programmes. As such, it is necessary to examine Taiwanese universities' intentions and strategies for offering and developing overseas programmes.

This paper seeks to clarify the rationale of Taiwanese universities offering overseas programmes as an internationalization strategy. The remainder of this paper is organized as follows. The next section reviews the literature on the internationalization of higher education in Taiwan, followed by an explanation of institutional analysis methodology. The fourth section presents an analysis of the state and characteristics of Taiwanese universities' overseas programmes. The universities' ideas and strategies for offering overseas programmes are then examined through a review of their development plans and the data obtained from semi-structured interviews. Based on its examination, this study offers suggestions concerning the internationalization policies of Taiwan. Elucidating the Taiwanese experience may also help in determining the feasibility of implementing cross-border education for universities in other East Asian countries.

National identity and ongoing contention between Mainland China and Taiwan's democratically elected government regarding Taiwanese sovereignty remain critical political issues (for more details, see Jiang 2017). However, Taiwan is different from other Chinese societies - such as Hong Kong, Macau, and Mainland China - in terms of their government and educational institutions, as well as their general political and economic contexts. This study selected Taiwanese society as its research subject in order to reveal the trend of internationalization in higher education institutions, analysing universities' overseas strategies of cross-border education programmes internationally and within the cross-strait. In this regard, some terms used in this paper require clarification. First, 'China' refers to the geographical area of this study, as well as Mainland China. 'Chinese' is employed as a relatively broad concept related to ethnicity and culture, and includes the overseas Chinese community, Malaysians of Chinese origin, Singaporean Chinese, and so on. In addition, section three provides greater detail regarding the institutional framework of overseas programmes and explains why the term 'Chinese students' used in this study does not include students from Mainland China.

\section{The Trend of Higher Education Internationalization in Taiwan}

Various definitions of higher education internationalization have arisen from different perspectives, rationales, activities, and strategies (de Wit \& Knight, 1999; de Wit, 2002; de Wit, Hunter, Howard, \& Egron-Polak, 2015; Knight, 2008; van der Wende, 1997). Knight (2008) defined the internationalization of higher education as 'the process of integrating an international, intercultural, and global dimension into the purpose, functions (teaching, research, and service), and delivery of higher education at the institutional and national levels' (p. xi). De Wit et al. (2015) revisited Knight's definition to argue that internationalization should not be a goal in itself; rather, it should enhance the quality of education and research and contribute meaningfully to society. This section concludes its review of the characteristics of higher education internationalization in Taiwan by addressing its development and the findings of related studies.

Influenced by the trends of globalization and a knowledge-based economy, Taiwanese society and its higher education institutions have faced growing international competition since the 1990s. Thus, the Taiwanese government began emphasizing the internationalization of higher education. The 'White Paper on Higher Education' - the first official document to respond to the internationalization issue - was promulgated in 2001 (Chan, 2011). This document argued that Taiwanese higher education should promote high academic standards, increase the recruitment of international students, and offer English curricula to mitigate its lack of internationalization (MOE, 2001). With Taiwan's entry into the World Trade Organization in 2002, policies concerning higher education internationalization were further emphasized to improve Taiwan's competition with other countries and expand its higher education market. The Taiwanese government designed the 'Plan for Promoting Universities' International Competitiveness' in 2002. The plan was Taiwan's first official internationalization policy, and its goal was to increase the university recruitment of overseas students and the provision of international courses. Afterwards, follow-up policies were promulgated in succession, including the 'Programme for Extending the Recruitment of Overseas Students' in 2004, the 'Southern Sunshine Policy' (i.e. the extension of the recruitment of overseas students from Southeast Asia) in 2008, and the 'Study-in-Taiwan Enhancement Programme' in 2011. The plan proposed establishing Taiwan as a higher education hub in East Asia and set a goal of enrolling 150,000 overseas students by 2020, which would account for $10 \%$ of the total number of university students in Taiwan (MOE, 2011). 
Based on these trends, Song and Tai (2007) and Lo (2009) have noted that the internationalization of Taiwanese higher education has predominantly focused on enhancing universities' academic standards and international competitiveness. Analysing two related policies, Song and Tai (2007) divided Taiwan's globalization strategies into two types: the development of top-notch universities and internationalization. The government has used financial subsidies to encourage higher education institutions to improve their academic standards, especially in the fields of science and technology. The internationalization of higher education has followed the same principle; that is, a strategy that can contribute to the universities' international competitiveness. Furthermore, Lo (2009) argued that trends in improving academic excellence and striving to create world-class universities could be observed in most Asian countries, including Taiwan. To some extent, however, this has resulted in Westernization and the domination of Anglo-American paradigms, which incur potential dangers associated with neo-colonialism. Lo thus proposed the concept of 'state-building universities' to address these issues. According to this concept, universities should focus on establishing state-building components, rather than striving to be world-class universities focused on joining the global community. State-building universities should emphasize the interactions and relationships between universities and local communities instead.

However, the ideology of internationalization in Taiwan differs from those of other Asian countries. Chan (2013) analysed and compared the higher education policies of Taiwan, Japan, Singapore, and Malaysia. He observed that while these countries have considered attracting international students as a strategy for stimulating national economic growth and improving international competitiveness, each has exhibited different implementation approaches. Taiwan and Japan have used independent strategies to expand their higher education markets to other countries, whereas Singapore and Malaysia have used cooperative strategies, emphasizing partnerships with Western universities. Therefore, Taiwan's and Japan's approaches have focused on strategies such as offering English courses, creating a foreign-student-friendly campus, and enhancing research and teaching, with the aim of internationalizing the higher education market by improving domestic higher education institutions.

The internationalization of higher education in Taiwan has also been shaped by local factors (Chen \& Lo, 2013; Chiang, 2014), one of which is the influence of domestic societal reform in the form of democratization and 'Taiwanization' on internationalization. The expansion of higher education in Taiwan in the context of low fertility is also a crucial factor. Chen and Lo (2013) interviewed professors from two science and technology universities to empirically study the process of internationalization in Taiwan. They argued that the internationalization activities in the lower tier of Taiwan's higher education sector were implemented for commercial reasons due to domestic factors such as a lack of resources and low student enrolment in universities. Moreover, from the perspective of university faculty and students, higher education internationalization should be more concerned with the quality of education and professional development than the pursuit of global standards (Chiang, 2014). These studies have mainly consisted of summaries of analysed policies. Few studies have focused on institutions and other stakeholders, most discussing the indicators of internationalization or quality assurance (Chin \& Ching, 2009; Ching \& Chin, 2012; Chin, Wu, \& Ching, 2012).

Based on the findings of the cited studies, internationalization in Taiwanese higher education, as well as that of other Asian countries, has been influenced by historical, political, and social factors and has emphasized competitiveness and the financial dimensions of internationalization (Deem, Mok, \& Lucas, 2008; Lo, 2009; Robert \& Palmer, 2011, Wong \& Wu, 2011). It has also focused on improving higher education exports and increasing universities' international reputations and competitiveness as the primary motives for internationalization.

\section{The Introduction and Institutional Framework of Taiwanese Overseas Programs}

This section examines the institutional framework of overseas programmes by analysing related policies and regulations. A summary of the background and an introduction to the overseas programmes is provided in this section.

To promote the recruitment of overseas students and create opportunities for international exchange, the MOE introduced overseas programmes through a revision of the 'Examination and Operation Directions of In-service Master's Degree Programs and In-service Two-year Technical Degree Programs' in 2003. Initially, overseas programmes could only be provided by specific types of universities in specific locations in East and Southeast Asia, and each educational stage of the programmes had different regulations governing their establishment and standards. However, the establishment of overseas programmes soon became deregulated through several amendments and newly promulgated regulations, which permitted any type of university to provide overseas programmes and removed regional restrictions. Thereafter, according to the 'Examination and Operation Directions of Institutions of Higher Education Applying and Establishing Overseas Programs' disseminated in 
2011 (although there were several subsequent amendments), the basic framework gave universities more authority over their own overseas programmes - providing they observed the following institutional framework (MOE, 2016b).

First, according to the latest 2016 directives, if universities prove that they have sound management and a balanced budget, and have not recently violated any government regulations, they can apply to host overseas programmes. Additionally, universities are only permitted to provide overseas programmes for fields in which domestic programmes are offered, and this permission is contingent upon their latest evaluation results being 'excellent' or 'satisfactory'. Second, their application to host overseas programmes has to be submitted annually. Therefore, the statuses of Taiwanese universities' overseas programmes have differed every year. Third, because of the unique political relationship between Mainland China and Taiwan (Chan, 2011), the recruitment targets are Taiwanese students and people of foreign nationality. With the exception of residents of Hong Kong and Macao, students from Mainland China are excluded from recruitment targets.

Considering the background of Taiwanese overseas programmes and related regulations confirms that the programmes are part of Taiwan's internationalization policy on higher education. Moreover, universities in Taiwan were able to develop their own overseas programmes under the pretext of internationalization. However, the quality of education is still regulated through the application process for the established and collaborating institutions.

\section{Methodology}

This section describes the research methods used to analyse the state and circumstances of overseas programs at an institutional level.

First, the number of overseas programmes and its students, and the recruitment document of universities are be analysed to illustrate the general overview of the current state and characteristics of Taiwanese universities overseas programmes. Second, the representative universities were selected as research objects based on the analysis above. The method of semi-structured interviews and related university documents is used to examine the intention of universities to offer and develop overseas programmes and the strategies employed. The respondents were universities administrators in charge of the overseas programme at these universities. Semi-structured interviews were conducted and comprised of four categories of questioning. (1) The background and idea of offering overseas programmes. (2) The strategies for developing overseas programmes, including strengths, weakness, opportunities, and threats of the overseas programme, the recruitment target, and the context of overseas programmes. (3) The state of overseas programmes, mainly focused on the overseas programmes' influence on the administration, organization, and faculty. The executive situation regarding student affairs and the structure of overseas programmes in terms of job occupation, financial and conferred-degree were also confirmed. (4) The future vision of overseas programmes. Moreover, the university documents utilised in this study mainly refer to the universities' development plan. These plans are usually available online, detailing the present state, orientation, mission, fundamental aims, and future vision of a university and its internal organizations. The rationale developed by these universities for offering overseas programmes as an internationalization strategy is discussed in the results section.

\section{Data Analysis}

\subsection{The Current State of Overseas Programmes}

This section analyses statistical data obtained from the MOE and recruitment documents produced by Taiwanese universities in 2015 to provide a general overview of the current state of Taiwanese universities' overseas programmes.

Records of the number of overseas programmes and their students are available from the MOE for 2007 in two statistical data sets: 'The Number of Overseas Students in Higher Education Institutions (Overseas Students Data)' and 'The Number of Students in Higher Education Institutions by Field of Study (Field of Study Data)' (Department of Statistics of the Ministry of Education [DSMOE], 2017b). However, neither of the data sets accurately depict the state of the overseas programmes because of the statistical method used. 'The Number of Overseas Students in Higher Education Institutions' accounts for only the number of foreign students, whereas Taiwanese, Hong Kong, and Macao students who enrolled in overseas programmes were excluded from the data set (Note 1). For instance, students enrolled in the National Taiwan University (NTU) overseas programme in China were Taiwanese; therefore, although the students of NTU overseas programme were accounted for in the Field of Study Data separately, this was excluded from the Overseas Students Data. Similarly, in the Field of Study Data of 2017, National Tsing Hua University had 25 students in the EMBA overseas programme in China 
(Guangdon) and five students in the Education and Technology overseas programme. However, the Overseas Students Data of 2017 only counted five students in overseas programmes of National Tsing Hua University. Moreover, determining the number of students enrolled in universities by field of study sometimes fails to account for students in overseas programmes, focusing only on field of study without distinguishing between domestic and overseas programmes (Note 2). As such, there is no consistency governing whether overseas programmes and their students are included in general programme data, and whether such information has been included or excluded cannot be distiguished. In addition, it was also difficult distinguishing Taiwanese students or not within the two data set.

However, the current state of the overseas programmes can be assessed to some extent by combining the two data sets. This study took the number of students enrolled in overseas programmes appearing on the university enrolment registers by field of study as a major data set and combined it with the number of overseas programme students appearing on the universities' registers of overseas students. The results of the analysis are shown in Figure 1.

According to these data, the current state of universities providing overseas programmes can be summarized as follows. First, only a few universities provided overseas programmes. Of the 144 universities in Taiwan in 2017, only 22 provided overseas programmes, accounting for merely 15\% of the total (DSMOE, 2017a). Second, the number of students studying in overseas programmes was minimal. Compared to the 664,854 students enrolled in higher education, the highest number of students in the overseas programmes only amounted to 1180 in 2017. Nevertheless, it should be noted that the number of both universities offering overseas programmes and students enrolled is increasing steadily.

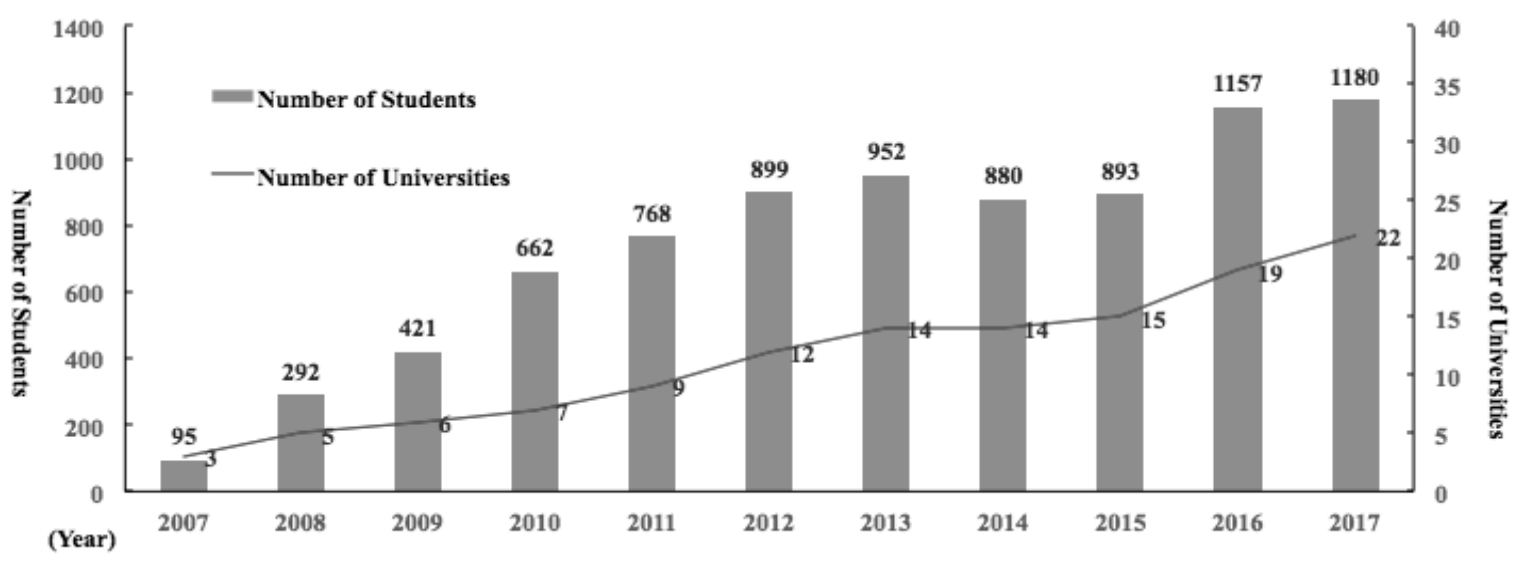

Figure 1. Number of students in overseas programmes and the number of universities with established overseas programmes [data adapted from DSMOE (2017b)]

\subsection{Analysis of Collected Data}

These points illustrate that Taiwan's overseas programmes have remained limited in scale and have only been provided by specific universities. The following section further evaluates the current circumstances of the examined universities based on an analysis of their application guidelines. As mentioned, Taiwan's universities must apply to the MOE for permission to provide overseas programmes every year. Since the universities providing overseas programmes have differed each year, it is difficult to accurately depict which types of overseas programmes Taiwanese universities offered over time. Despite this difficulty, the homepages of 145 universities (the total number of universities in Taiwan as of 2015) were accessed within the four-day period of 6-9 December 2015; information was thus predominantly obtained from the webpages of the universities' recruitment centres, lifelong education and training centres, and international affairs centres.

The results show that 11 universities displayed recruitment information for their overseas programmes. However, two universities were not currently providing overseas programmes because of disturbances in receipt countries and a lack of recruitment capacity; thus, they were excluded from the analysis. Nine universities were currently providing overseas programmes at the time of research, as indicated in Table 1 (Note 3). With the exceptions of Shin Hsin University, Shu-Te University (STU), and Chinese Culture University, these universities were national 
universities. All of the universities were prestigious or historic in Taiwan. These universities offered overseas programmes by collaborating with institutions in receipt areas, all of which are also certificated institutions or prestigious universities. For example, all of the collaborating institutions in China were selected by Project 985 and Project 211; the projects usually selected those that were top-ranking and highly approved by Chinese society, thus allocating large amounts of funding to the selected institutions to enhance research standards and cultivate world-class universities.

Table 1. Overseas Programs Offered in 2015

\begin{tabular}{|c|c|c|c|c|c|}
\hline Institution & $\begin{array}{l}\text { Field of overseas } \\
\text { program offered }\end{array}$ & $\begin{array}{l}\text { Year } \\
\text { established }\end{array}$ & $\begin{array}{l}\text { Established } \\
\text { region }\end{array}$ & $\begin{array}{l}\text { Collaborating } \\
\text { university }\end{array}$ & Language(s) \\
\hline $\begin{array}{l}\text { National Taiwan } \\
\text { University }\end{array}$ & $\begin{array}{l}\text { NTU-FDU EMBA } \\
\text { (Executive Master of } \\
\text { Business Administration) }\end{array}$ & 2010 & $\begin{array}{l}\text { China } \\
\text { (Shanghai) }\end{array}$ & Fudan University & $\mathrm{C}$ \\
\hline $\begin{array}{l}\text { National Chung Hsing } \\
\text { University }\end{array}$ & $\begin{array}{l}\text { Cross-strait EMBA for } \\
\text { Taiwanese Businesspeople }\end{array}$ & 2012 & $\begin{array}{l}\text { China } \\
\text { (Shanghai) }\end{array}$ & $\begin{array}{l}\text { Shanghai Academy of Social } \\
\text { Sciences }\end{array}$ & $\mathrm{C}$ \\
\hline $\begin{array}{l}\text { National Sun Yat-sen } \\
\text { University }\end{array}$ & Cross-strait EMBA & 2011 & $\begin{array}{l}\text { China } \\
\text { (Shanghai) }\end{array}$ & Tongji University & $\mathrm{C}$ \\
\hline \multirow[t]{2}{*}{ Shin Hsin University } & Business Administration & 2010 & $\begin{array}{l}\text { China } \\
\text { (Shanghai) }\end{array}$ & Tongji University & $\mathrm{C}$ \\
\hline & $\begin{array}{l}\text { Communications } \\
\text { Management }\end{array}$ & 2010 & $\begin{array}{l}\text { China } \\
\text { (Shanghai) }\end{array}$ & Tongji University & $\mathrm{C}$ \\
\hline \multirow{3}{*}{$\begin{array}{l}\text { National Taipei } \\
\text { University of } \\
\text { Technology }\end{array}$} & EMBA & 2013 & Thailand & $\begin{array}{l}\text { King Mongkut's University } \\
\text { of Technology Thonburi }\end{array}$ & $\mathrm{C}, \mathrm{E}$ \\
\hline & $\begin{array}{l}\text { Industrial Engineering and } \\
\text { Management EMBA }\end{array}$ & 2014 & $\begin{array}{l}\text { China } \\
\text { (Guangdong) }\end{array}$ & Sun Yat-sen University & $\mathrm{C}$ \\
\hline & EMBA & 2015 & $\begin{array}{l}\text { China } \\
\text { (Shanghai) }\end{array}$ & Soochow University & $\mathrm{C}$ \\
\hline \multirow[t]{2}{*}{$\begin{array}{l}\text { National Chi Nan } \\
\text { University }\end{array}$} & EMBA & 2011 & China (Wuhan) & $\begin{array}{l}\text { Huazhong University of } \\
\text { Science and Technology }\end{array}$ & $\mathrm{C}$ \\
\hline & Counselling Psychology & 2006 & Singapore & $\begin{array}{l}\text { Academy of Human } \\
\text { Development }\end{array}$ & $\mathrm{C}$ \\
\hline National Changhua & School Administration & 2008 & Malaysia & New Era University College & $\mathrm{C}$ \\
\hline University of Education & $\begin{array}{l}\text { Creative Teaching of } \\
\text { Mathematics }\end{array}$ & 2015 & Malaysia & New Era University College & $\mathrm{C}$ \\
\hline Shu-Te University & Human Sexuality & 2014 & Malaysia & New Era University College & $\mathrm{C}$ \\
\hline Chinese Culture & Political Science \& & 2015 & China (Macao) & Macao Polytechnic Institute & \\
\hline University & Governance & & & & \\
\hline
\end{tabular}

Note: $\mathrm{C}=$ Chinese, $\mathrm{E}=$ English

Among the universities, 14 overseas programmes were offered, all of which were in-service master's degree programmes. According to the data displayed in Table 1, these programmes can be divided into two types: overseas programmes for overseas Taiwanese citizens and programmes for overseas students.

Programmes of the first type are mostly found in Mainland China and mainly comprise management degree programmes. Moreover, because Mainland China's students are not permitted to be recruitment targets, Taiwanese citizens are the main recruitment targets. Indeed, of the total number Taiwanese people working abroad in 2016, some 407,000 (55.9\%) were in China (National statistics, 2018).

Programmes of the second type-which target overseas students-are primarily in Southeast Asia, especially Malaysia, and span a wide range of fields including education, administration, psychology, and the natural sciences. Compared with overseas programmes in Mainland China, these programmes offer a wider variety of curricula, mainly in response to the demand of overseas students. Furthermore, such students are mainly of Chinese origin because the instructional language is Chinese. Although the National Taipei University of Technology (NTUT) overseas programme in Thailand uses English as one of its instructional languages, the classes taught in English account for only $10 \%$ of the curriculum.

Evidently, the two types of overseas programmes have different purposes and characteristics. The examined universities have provided and developed overseas programmes with different strategies, and the programmes 
can be roughly divided into two groups according to the type of programme offered. The first group of universities offering programmes for Taiwanese students includes NTU, National Chung Hsing University, National Sun Yat-sen University, Shin Hsin University, and NTUT. While the second group targets overseas students, they primarily co-operate with Southeast Asian universities or educational institutions and span a wide range of degree programmes. Such universities include National Changhua University of Education (NCUE), STU, and Chinese Culture University. By offering two types of overseas programmes, National Chi Nan University (NCNU) has utilized internationalization strategies that are more comprehensive than those of the other universities. Although NTUT and NCNU have both provided two types of overseas programmes, NTUT chose overseas Taiwanese as its main target for offering overseas programmes in the field of management.

\subsection{Case-study Analysis of the Five Universities}

Based on the overview in the previous section, there are two types of offering tactics among the participating universities. To uncover further details regarding the functions of the overseas programmes in Taiwan's universities, case-study research was undertaken through an examination of five universities.

The five universities in the case-study analysis were NTU, NTUT, NCNU, NCUE, and STU. The reasons for examining these institutions are as follows. First, NTU and NTUT are current examples of universities offering programmes for Taiwanese overseas students. NTU can be considered a representative model because it was the first university to provide an overseas programme in China, and other universities in Taiwan soon followed their lead (Wu, Wang, Tsai, \& Ren, 2013). However, since NTUT established overseas programmes in locations that were more diverse and with institutions that were more cooperative, the university has devised strategies that are more peculiar than those of other universities offering overseas programmes for Taiwanese people. Therefore, the two universities were taken as the first case study. In contrast, NCUE and STU were taken as current examples of the group of universities offering overseas programmes for overseas students. NCUE and STU offered programmes in Malaysia in partnership with New Era University College, with NCUE notably offering programmes earlier than other universities. These universities have had strategies that are more clearly defined than those of others. NCNU was also selected as a model case study because it had more comprehensive strategies than the other universities, with both the internationalization and provision of education for overseas Chinese emphasized in its literature (https://www.gazette.ncnu.edu.tw/about_ncnu).

Table 2. Respondents of the Five Case Study Universities

\begin{tabular}{llllll}
\hline Institutions & NTU & NTUT & NCNU & NCUE & STU \\
\hline Respondents & A & B & C, D & E & F \\
\hline
\end{tabular}

Most of the case study universities provided overseas programmes in only one field; thus, its overseas programmes were managed by a specific college or school in the university. However, NCNU offered overseas programmes in two different fields and they were managed by two different institutions. Therefore, as reflected in Table 2, one respondent was selected for each university except NCNU, which has two. Consequently, six respondents were selected to represent the five universities. These respondents were in charge of the overseas programmes, and most also held positions as a dean or supervisor of the programme-providing institution. Their perspectives were strongly connected to the ideas or strategies of implementing overseas programmes in each university.

\section{Results}

\subsection{Different Approaches to Internationalization among the Case Study Universities}

As noted, the five case study universities have adopted different approaches to internationalization. These strategies, as evidenced by their overseas programmes, are described in this section.

NTU was established in 1928, and became the most prestigious university in Taiwan. Being 'the top-notch university of Asia and the world-class university of the world' became the university's goal, and it positioned itself as a research university with a high degree of internationalization (NTU, 2014). Under this principle, NTU's College of Management regarded overseas programmes as one of its means of achieving internationalization (NTU, 2014). In 2011, NTU created the NTU-FDU Executive Master of Business Administration (EMBA) overseas programme in cooperation with Fudan University to cultivate high-level management talents in a global, interdisciplinary, innovative, and progressive programme (NTU, 2014). Furthermore, according to interview results, the university intends to further increase its influence in China through its long-term cooperation with Fudan University. 
NTUT offers overseas programmes to enhance internationalization and maintain its international alumni network. (This point is described in further detail subsequently.) The NTUT approach to internationalization involves cooperating with foreign universities to establish connections and increase academic exchange (NTUT, 2013). For example, the university views its overseas programme in Guangdong Province as an opportunity to develop further agreements on exchange credits or double degrees with Sun Yat-sen University and the Harbin Institute of Technology (NTUT, 2012). Moreover, providing overseas programmes for NTUT alumni, most of whom occupy high positions in companies, could increase industry-academia collaboration with major local companies and contribute towards enhancing NTUT's reputation (NTUT, 2014, 2015).

NCUE's purpose for providing an overseas programme is related to increasing the number of overseas students (NCUE, 2013). In addition, NCUE has been dedicated to forming a connection with Chinese independent high schools in Malaysia by offering educational support for teacher training and an educational quality assurance framework among other endeavours (NCUE, 2013).

Although no overseas programme was mentioned in STU's development plan, Asia's first graduate school of sexual science, which also provides an overseas programme, was emphasized (https://www.stu.edu.tw/aboutstu.php?lang=zh_TW). According to the administrator in charge, the purposes of offering the overseas programme included increasing the school's reputation in Asia and extending the academic influence of sexual science. The programme could also serve to increase their recruitment of overseas students, thus easing enrolment concerns stemming from the low birth rate in Taiwan.

As mentioned, NCNU has offered both types of overseas programmes, thereby presenting a more comprehensive internationalization strategy. NCNU's strategy has been based on strengthening the cultivation of human resources, enhancing the function of educational support for overseas Chinese students, balancing the development of the local community, and promoting international academic exchange (http://www.ncnu.edu.tw/ncnuweb/). Among these principles, providing educational support for Chinese overseas students was thought to be the characteristic of NCNU's strategy that would contribute most towards developing internationalization (NCNU, 2012). NCNU has also emphasized strengthening overseas education to enhance international cooperation and exchange. Based on these strategies, the university provided overseas programmes in both Singapore and China in 2006 and 2011.

To summarize, these universities have offered overseas programmes with goals of internationalization. Nevertheless, the approaches to internationalization among the five case study universities differed significantly based on the type of overseas programmes they offered. The universities offering Taiwanese overseas programmes in Mainland China have placed more emphasis on enhancing academic exchange and cooperation with partner educational institutions, as well as on strengthening institutional prestige, thus exemplifying the indirect influence of offering overseas programmes. In contrast, the universities offering overseas programmes in Southeast Asia have focussed on increasing the number of overseas students, offering overseas programmes to contribute to internationalization efforts.

\subsection{Common Trends in Offering Overseas Programmes}

Despite the different approaches to internationalization, the examined universities exhibited similar tendencies in their strategies for overseas programmes, as summarized in the following subsections.

\subsubsection{Creating Overseas Programs Based on Existing Resources and Needs}

The five case study universities offered overseas programmes to respond to existing learning needs and create more appropriate curricular content and educational environments. These learning needs were related to domestic programmes or networks that had already been established. The details are as follows.

First, the overseas programmes were offered as an extension of the domestic EMBA programmes in order to respond to the overseas educational needs of Taiwanese businesspeople, whose increased presence in China has resulted from gradually improving cross-strait relations and economic exchange since 2008. Furthermore, after the Cross-Strait Economic Cooperation Framework Agreement was signed in 2010, Taiwanese companies began to enter the Chinese market more actively. Consequently, it has become necessary to offer education that could be more adaptable to the EMBA programmes' primary recruitment targets: Taiwanese executives and businesspeople living in China. In this context, NTU and NCNU began offering overseas programmes to respond to the learning needs of the primary recruitment targets - executives and businesspeople in China-as they confirmed in interviews. Respondent A stated the following:

The College of Management at NTU in cooperation with Fudan University, offered the overseas programme to meet the needs of the gradually increasing number of Taiwanese businesspeople in China, 
to help them realize industry-related policies, and to build a network in China (Personal communication, 3 June 2016).

The EMBA overseas programme manager for NCNU, respondent C, made a similar point concerning the reasons for offering an overseas EMBA programme at NCNU adapted to the needs of Taiwanese business managers:

Now business managers do not stay in Taiwan all the time. Instead, they travel around China or other countries because of the industrial changes within globalization and the trend of Taiwanese companies gradually expanding overseas. Thus, it is difficult for them to enrol in a domestic programme, because they would have to attend classes every week (Personal communication, 7 June 2016).

Thus, to meet the needs of Taiwanese businesspeople, NCNU began providing EMBA overseas programmes to allow them to take classes in person regularly.

The second point concerns previously established networks. NTUT began offering overseas programmes in Thailand and China (Guangdong Province and Shanghai) from 2013 to 2015, as a response to the educational needs of overseas alumni. This strongly influenced by the university's development strategy and recruitment considerations. Since $10 \%$ of the owners of Taiwanese companies are NTUT alumni, the alumni network was emphasized in their development plan (http://info.ntut.edu.tw/files/11-1139-7530.php). Moreover, meeting the learning needs of alumni was also related to ensuring enrolment. Respondent B mentioned that these alumni had a sense of belonging in the university and showed a willingness to attend the overseas programmes. As such, this is an effective way of reaching out to the international community and extending the influence of a university's overseas programmes based on its network of overseas alumni.

The provision of overseas programmes at NCUE stems from its history of collaboration and exchange with Malaysia, having supported the education of Malaysian Chinese people for over a decade. Its co-operation with Malaysia also forms the basis of the university's internationalization strategy. The university's development plan mentioned plans for promoting further practical exchange with foreign universities or educational organizations in the future, especially in offering overseas educational programmes in Malaysia, as well as cultivating exchange with and cooperation in other areas (NCUE, 2016). NCUE thus signed a letter of intent with New Era University College in 2006, subsequently offering an overseas programme offered on this basis.

NCNU and STU already had established networks when they began offering overseas programmes. The respondents from both institutions mentioned that offering overseas programmes resulted from faculty having established exchanges or cooperative relationships with foreign countries by, for example, delivering presentations, organizing workshops, and providing credit courses. Based on these activities, NCNU and STU began offering overseas programmes.

\subsubsection{The Role of Culture and Values of Taiwanese society in Overseas Programmes}

The culture and values of Taiwanese society have played a substantial role in the development of overseas programmes. Although exhibited differently from one university to another, this influence can be categorised into Chinese elements and pluralistic values in Taiwanese society. Such elements were used to strengthen academic influence and develop overseas student markets.

As Lo (2016) mentioned, within the context of globalization and modernization, asserting the value of 'Chineseness' has been considered a powerful response to the trend of Westernization in the Asia-Pacific region. A similar trend was observed among the case study universities. One of the goals of offering overseas programmes at NTU and NCNU has been to shape their specific fields according to the elements of the Chinese language and culture shared by Taiwan and several other countries in the region.

NTU provided overseas programmes not only to respond to the Taiwanese business market, but also to establish a Chinese model of management education. NTU's respondent said their management programme may offer some advantages in Southeast Asia and China by taking the lead in the educational context and implementing teaching materials and methods. They also noted their institution's vision of establishing a Chinese model:

In management education, you cannot lose contact [with society]. If you keep in touch with society, new types of management models in emerging markets can be developed. We will never understand the viewpoint of local management in the East if we use only a Western point of view and do not maintain contact with society. This is also related to research. If you want to contribute to research, it is necessary to approach the market so that you can develop Mainland China's, Chinese, or emerging types of management (Personal communication, 3 June 2016).

Similarly, NCNU, which has offered overseas programmes in Singapore, has also adopted Chinese consultation 
and counselling for the following two reasons. The first concerns the strategy of market segmentation. In an interview, respondent D described how offering a programme in the Chinese language for Singaporean Chinese students (as the primary recruitment target) was a strategy used to divide the market between the programmes they have offered and similar programmes in English provided by Australia National University. The second reason involves integrating the educational contexts and raising the influence of the Chinese counselling field. Respondent D mentioned that although both Taiwanese and Singaporean Chinese people are ethnically Chinese, Singaporean Chinese exhibit different ways of thinking and come from a different environment and cultural background. Therefore, NCNU sought to determine how counselling theories and skills should be adjusted for Chinese students from different societies. Moreover, providing overseas programmes increased exchange with Singaporeans, and helped reveal the remaining obscurities in the Chinese counselling field by combining theory and practice (Personal communication, 6 June 2016). NCNU also established the Chinese Consultative Association in Singapore to enhance its connections and influences therein.

STU's strategy differs from those of NTU and NCNU because it is based on the advanced pluralistic values of Taiwanese society, which differ from those of other Asian countries. STU has offered an overseas programme in the field of sexual science, which is not available at universities in other Asian countries. Indeed, Respondent F noted that STU has the only graduate school of human sexuality in Asia. They explained that this is likely due to the traditional social and cultural values in other Asian nations, which may prevent the establishment of such programmes. Taiwan is thus leading the region in the field of sexual science. As such, there is an advantage in offering educational support and resources to other Asian countries in order to raise STU's academic prestige in the field of sexual science (Personal communication, 6 June 2016).

The consideration of language and values is another reason for using Chinese as an overseas programme's language of instruction. The respondents from both NTU and STU mentioned that using Chinese as the teaching language is the best and most efficient way of delivering curricular content, particularly in comparison to English or other languages that would require translation. Moreover, although restricted by the initial rules governing the establishment of overseas programmes, NTU chose China-rather than a Southeast Asian country-as the first location for its overseas programme because of cultural approximation.

Expanding the overseas student market by offering overseas programmes has also been influenced by the idea of 'Chineseness'. As a result of the shared language and culture between Taiwanese and Malaysian people, NCUE has considered Malaysian Chinese students to be the primary targets for increasing their recruitment of overseas students. Respondent E stated the following:

The system of Chinese independent high schools had more than 80,000 students. It will contribute not only to NCUE's student pool but also to Taiwan's. Furthermore, it could ease the lack of enrolment at NCUE to some extent (Personal communication, 6 June 2016).

As mentioned, NCUE has offered educational support to Malaysian Chinese for more than a decade. Furthermore, the overseas programmes were mainly provided for teachers and administrators of Chinese independent high schools. The university considered using this connection to increase the enrolment of Chinese independent high school students at NCUE, which would also raise the number of overseas students.

In summation, although the five case-study universities adopted different strategies in their overseas programmes, they share a common mechanism. The individual characteristics and circumstances of institutions, as well as the history, culture, and values of Taiwanese society, have influenced these universities' strategies regarding overseas programmes.

\section{Conclusion}

The rationales driving internationalization can be categorized into national and institutional levels (Knight, 2008). With the increasing globalization of research and knowledge, both national and global entities, as well as higher education institutions, are playing increasingly vital roles in the internationalization process and its outcomes (Marginson, 2010). Based on this study's analysis of several Taiwanese institutions' overseas programme strategies, the following conclusions can be drawn. First, the strategies of overseas programmes offered by Taiwanese universities have varied. More than pursuing academic excellence and expanding student markets, as consistent with the findings of the previous studies cited in the introduction, the ideas of ensuring industryuniversity cooperation, providing educational support, and developing local models have been emphasized in university strategies. Second, the provision and implementation of these strategies have been influenced by both government policies and rationales based on institutional history, resources, development goals, and related local values and culture, which constitute a fundamental dynamic of higher education internationalization. 
Several scholars (Mok, 2007; Lo, 2009; Ng, 2012) have argued that following the trend of the Anglo-American paradigm in the internationalization of higher education in East Asian may lead to Westernization, Americanization, or Western-dominance. In examining how institutional goals, characteristics, and contexts affect the internationalization of higher education, this study has illustrated that Taiwanese institutions tend to implement internationalization based on the Chinese element and the pluralistic values of Taiwanese society. The result of this empirical investigation suggests that merely adopting the general ideas of enhancing international competition or increasing student recruitment is insufficient. It is essential for higher education institutions to implement internationalization strategies through a critical understanding of their meaning and purpose in the context of higher education institutions, and to develop an internationalization approach based on the unique values and culture of their own society. In doing so, academically peripheral countries can advance internationalization without succumbing to the dangers of Westernization or Western domination.

\section{Acknowledgments}

The author thanks the interviewees for contributing their time and insights to the study. In addition, the author would like to thank Professor Leeh Ter Yao, Professor Wu Hsun Yang, and Assistant Professor Yu Hung Cheng for their assistance with this study.

\section{References}

Chan, S. J. (2011). Cross-border educational collaboration between Taiwan and China: The implications for educational governance. Asia Pacific Journal of Education, 31(3), 311-323. https://doi.org/10.1080/02188791.2011.594422

Chan, S. J. (2013). Internationalising higher education sectors: Explaining the approaches in four Asian countries. Journal of Higher Education Policy and Management, 35(3), 316-329. https://doi.org/10.1080/1360080X.2013.786854

Chen, I. R. (2013). Regional cooperation or the extension of domestic education? The implementation of offshore education in Taiwan. In K. H. Mok \& K. M. Yu (Eds.), Internationalization of higher education in East Asia: Trends of student mobility and impact on education governance (pp. 192-207). London, UK: Routledge.

Chen, I. R., \& Lo, W. Y. W. (2013). Internationalization or commodification? A case study of internationalization practices in Taiwan's higher education. Asia Pacific Education Review, 14(1), 33-41. https://doi.org/10.1007/s12564-013-9246-0

Chiang, L. (2014). The critical study on the internationalization of higher education in Taiwan. In A. Kwan, E. Wong, T. Kwong, P. Lau, \& A. Goody (Eds.), Research and development in higher education: Higher education in a globalized world: 37(94-104). Hammondville, AU: Higher Education Research and Development Society of Australasia.

Chin, J. M. C., \& Ching, G. S. (2009). Trends and indicators of Taiwan's higher education internationalization. The Asia-Pacific Education Researcher, 18(2), 185-203. https://doi.org/10.3860/taper.v18i2.1322

Chin, J. M. C., Wu, C. T., \& Ching, G. S. (2012). Apples and oranges: Comparison of Taiwan higher education institutions' internationalization. International Journal of Research Studies in Education, 1(2), 3-22. https://doi.org/10.5861/ijrse.2012.v1i2.24

Ching, G. S., \& Chin, J. M. C. (2012). Managing higher education institution internationalization: Contemporary efforts of a university in Taiwan. International Journal of Research Studies in Management, 1(1), 3-16. https://doi.org/10.5861/ijrsm.2012.v1i1.9

Deem, R., Mok, K. H., \& Lucas, L. (2008). Transforming higher education in whose image? Exploring the concept of the 'world-class' university in Europe and Asia. Higher Education Policy, 21(1), 83-97. https://doi.org/10.1057/palgrave.hep.8300179

DSMOE. (2017a). Education Statistics: The Republic of China 2017. Taipei: Ministry of Education. (Chinese)

DSMOE. (2017b). The basic data of higher education institutions in Taiwan. Retrieved from https://depart.moe.edu.tw/ed4500/News.aspx?n=5A930C32CC6C3818\&sms=91B3AAE8C6388B96

De Wit, H., \& Knight, J. (Eds.). (1999). Quality and internationalisation in higher education. Paris: Organisation for Economic Cooperation and Development.

De Wit, H. (2002). Internationalisation of higher education in the United States of American and Europe: A historical, comparative, and conceptual analysis. Westport, CT: Greenwood. 
De Wit, H., Hunter F., Howard L., \& Egron-Polak E. (Eds.). (2015). Internationalisation of higher education. Brussels: European Parliament.

Jiang, Y. (2017). Taiwan's National Identity and Cross-Strait Relations. In Dittmer, L. (Ed.), Taiwan and China: Fitful Embrace (pp. 19-41). Oakland, California: University of California Press. https://doi.org/10.1525/luminos.38.b

Knight, J. (2008). Higher education in turmoil: The changing world of internationalisation. Rotterdam, The Netherlands: Sense Publishers.

Lo, W. Y. W. (2009). Reflections on internationalisation of higher education in Taiwan: Perspectives and prospects. Higher Education, 58(6), 733-745. https://doi.org/10.1007/s10734-009-9209-x

Lo, W. Y. W. (2016). The concept of greater China in higher education: adoptions, dynamics and implications. Comparative Education, 52(1), 26-43. https://doi.org/10.1080/03050068.2015.1125613

Marginson, S. (2010). Higher education in the global knowledge economy. Procedia Social and Behavioral Sciences, 2(5), 6962-6980. https://doi.org/10.1016/j.sbspro.2010.05.049

MOE. (2001). The White Paper of University Education Policy. Taipei, Ministry of Education. (Chinese)

MOE. (2011). Study-in-Taiwan Enhancement Program. Taipei, Ministry of Education. (Chinese)

MOE. (2016a). New Southward Human Resource Development Program. Taipei: Ministry of Education. (Chinese)

MOE. (2016b). The examination and operation directions of junior colleges and institutions of higher education applying and establishing overseas programs. Retrieved from http://edu.law.moe.gov.tw/LawContent.aspx?id=FL042667_(Chinese)

Mok, K. H. (2007). Questing for Internationalization of University in Asia: Critical Reflections. Journal of Studies in International Education, 11(3-4), 433-454. https://doi.org/10.1177/1028315306291945

National Statistics. (2018). The statistics of working-abroad Taiwanese in 2016. Retrieved from https://www.stat.gov.tw/ct.asp?xItem $=42426 \& c t N o d e=6395 \& \mathrm{mp}=4$ (Chinese)

NCUE. (2013). Report on attending the ceremony and visiting five schools in Malaysia. Retrieved from https://report.nat.gov.tw/ReportFront/ReportDetail/detail?sysId=C10301223 (Chinese)

NCUE. (2016). National Changhua University of Education medium and long-term school development plan. Retrieved from http://rnd.ncue.edu.tw/ezfiles/2/1002/img/707/104691272.pdf (Chinese)

NCNU. (2012). NCNU Evaluation. Retrieved from http://staffweb.ncnu.edu.tw/hdcheng/evaluation/index.html (Chinese)

$\mathrm{Ng}$, S. W. (2012). Rethinking the mission of internationalization of higher education in the Asia-Pacific region. Compare: A Journal of Comparative and International Education, 42(3), 439-459. https://doi.org/10.1080/03057925.2011.652815

NTUT. (2012). The cooperation and exchange about offering overseas programs with EMBA of Guangzhou Sun Yat-sen University and graduate school of Shenzhen Harbin Institute of Technology. Retrieved from https://report.nat.gov.tw/ReportFront/ReportDetail/det ail?sysId=C10101682 (Chinese)

NTUT. (2013). Report on visiting cooperating schools and the graduates' association. Retrieved from https://report.nat.gov.tw/ReportFront/ReportDetail/detail?sysId=C10203268 (Chinese)

NTUT. (2014). Report on visiting cooperating schools and attending the opening ceremonies of EMBA overseas programs in Thailand. Retrieved from https://report.nat.gov.tw/ReportFront/ReportDetail/detail?sysId=C10 302905 (Chinese)

NTUT. (2015). Recruitment orientation for overseas programs in Dongguan. Retrieved from https://report.nat.gov.tw/ReportFront/ReportDetail/detail?sysId=C10400630 (Chinese)

NTU. (2014). The mid-range development plan from 2014 to 2018. Retrieved from https://www.ntu.edu.tw/about/statistics.html (Chinese)

Roberts, A., \& Palmer, J. D. (2011). Introduction: Ideologies of the globalization and internationalization of higher education: An East Asian context. In J. D. Palmer, A. Roberts, Y. A. Cho, \& G. S. Ching (Eds.), The internationalization of East Asian higher education (pp. 1-9). New York, NY: Palgrave Macmillan. https://doi.org/10.1057/9781137002006_1 
Song, M. M., \& Tai, H. H. (2007). Taiwan's responses to globalisation: Internationalisation and questing for world class universities. Asia Pacific Journal of Education, 27(3), 323-340. https://doi.org/10.1080/02188790701594067

van der Wende, M. C. (1997). Missing links. The relationship between national policies for internationalisation and those for higher education in general. In T. Kaelvemark \& M. van der Wende (Eds.), National policies for the internationalisation of higher education in Europe (pp. 10-31). Stockholm, Sweden: National Agency for Higher Education.

Wong, M. S., \& Wu, S. F. (2011). Internationalization of higher education in East Asia: Issues, implications, and inquiries. In J. D. Palmer, A. Roberts, Y. A. Cho, \& G. S. Ching (Eds.), The internationalization of East Asian higher education (pp. 1-9). New York, NY: Palgrave Macmillan. https://doi.org/10.1057/9781137002006_9

Wu, X. L., Wang, Z. S., Tsai, J. Z., \& Ren, B. R. (2013). White Paper on assessing the policy of recruiting mainland students [In Chinese]. Retrieved from http://www.cppl.ntu.edu.tw/research2012.html

\section{Notes}

Note 1. This information was confirmed by the Department of Statistics of the Ministry of Education (Personal communication, 4 September 2018, 20 August 2018, and 11 November 2015).

Note 2. This information was confirmed by the Department of Statistics of the Ministry of Education (Personal communication, 10 November 2015).

Note 3. While the collected information shows that one of the universities offered overseas bachelor's degree programmes in Vietnam, these programmes were provided by a cooperating foreign university and the applicants were limited to students from that university. Recruitment documents were also unavailable. Therefore, this university was excluded from the analysis (Personal communication, 8 January 2016).

\section{Copyrights}

Copyright for this article is retained by the author(s), with first publication rights granted to the journal.

This is an open-access article distributed under the terms and conditions of the Creative Commons Attribution license (http://creativecommons.org/licenses/by/3.0/). 